\title{
Impact of Computer-Aided Warfarin Dosing in a Saudi Arabian Cardiac Centre
}

\author{
Ahmad A Almeman ${ }^{1,2^{*}}$ and S Rasool ${ }^{2}$ \\ ${ }^{1}$ School of Pharmacy, Qassim University, ${ }^{2}$ Anticoagulation Clinic, Prince Sultan Cardiac Center (PSCC), Buraidah, Al Qassim, \\ Kingdom of Saudi Arabia.
}

*For correspondence: Email: ahmadalmeman@gmail.coml; seemab.rasool@gmail.com; Tel: 00966548889712; Fax: 0096663800662

\begin{abstract}
Purpose: To compare the efficacy of computer-aided dosing using Coagclinic (a web-based software) with physician dosing in patients receiving warfarin for various cardiac indications.

Methods: In order to calculate the effectiveness of physician managed anticoagulation dosing, we calculated the "percentage of time international normalized ratio, INR, was in the therapeutic range" (TTR) for a random sample of 70 patients in the center. For each patient, 4 INR values were taken at 4 consecutive visits, before and after the installation of Coagclinic. Data on the doses given by physicians were collected at each visit and compared them with the pharmacy-based computer aided dosing system data.

Results: After performing paired samples t-test of doses based on the physician group with those based on the computer system (mean $-1.5654 \pm 2.09$ ), a statistically significant difference was found ( $p<$ 0.015). Furthermore, the patients kept at TTR by physicians amounted to $26 \%$ compared to $70 \%$ by the software.

Conclusion: The difference between TTR managed by physicians and those managed using CoagClinic ${ }^{\mathrm{TM}}$ software is statistically significant. It appears that the software improves the effectiveness of warfarin dosing in patients.
\end{abstract}

Keywords: Anticoagulation, Computer dosing, Physician dosing, Cardiac, Warfarin.

Tropical Journal of Pharmaceutical Research is indexed by Science Citation Index (SciSearch), Scopus, International Pharmaceutical Abstract, Chemical Abstracts, Embase, Index Copernicus, EBSCO, African Index Medicus, JournalSeek, Journal Citation Reports/Science Edition, Directory of Open Access Journals (DOAJ), African Journal Online, Bioline International, Open-J-Gate and Pharmacy Abstracts

\section{INTRODUCTION}

Warfarin is a vitamin $\mathrm{K}$ antagonist widely used worldwide for many clinical disorders including atrial fibrillation (AF) $\left.{ }^{1}\right]$. Many patients with AF and other thrombotic disorders have not been able to receive this treatment or have only been treated for a restricted period due to their large numbers; secondly, resources for anticoagulant administration are limited. The efficacy and safety of vitamin K antagonists (VKA) are related to the actual level of anticoagulation given as the international normalized ratio (INR). It is often difficult to maintain an optimal INR over time $\left[{ }^{2}\right]$. In many countries, health care facilities have turned to a range of commercial and non-commercial computer-assisted dosage programs (CDSSs) to facilitate anticoagulation dosing by nurses, pharmacists and laboratory technologists.

Computer programs that predict dosage adjustments of oral anticoagulants and the time interval to the next test have been 
shown to improve the quality and efficiency of oral anticoagulation therapy OAT and are being increasingly used in practice[10-15] . CoagClinic ${ }^{\mathrm{TM}}$ is a well known web based software that offers a web-based, customizable approach to the management and documentation of anticoagulation therapy. The main benefits include tracking use of approved protocols, patient-specific support for warfarin and low molecular weight heparin dosing and documentation of patient education for follow up monitoring, adherence tracking and counseling regarding nutrition as well as compliance and drug-drug interactions (DDI's)[3].

Though there are many studies showing superiority of CDSSs in many aspects of medical care, not many studies have been undertaken to demonstrate their effect on patient outcome [11-17]. CDSSs are in use in many countries but not in Saudi Arabia Lastly, the efficacy of OAT depends not only on defining the target INR but also maximizing the length of time the patient's INR is maintained within the designated therapeutic range TTR[4]. Therapeutic INR range (TTR) is a way of summarizing INR control over time. TTR has been studied mostly in the setting of clinical trials where it is used to evaluate the effectiveness of warfarin therapy. However, TTR has been underutilized as a quality measure. Infact, there has been a general lack of quality evaluation and monitoring in oral anticoagulation clinics. There is much evidence that better anticoagulation control (i.e., higher TTR) can protect patients from severe or even fatal adverse events [5].

Our study aims to analyze the application of computer software-aided anticoagulation dosing in Saudi Arabia and its effect on the time that blood levels of the administered drug remains in the therapeutic range (TTR).

\section{EXPERIMENTAL}

A prospective interventional clinical study was conducted to investigate the impact of computer-assisted Warfarin dosing compared to routine clinical dosing by physicians. The ethical approval for the study was obtained from the ethical committee in King Fahad Specialist Hospital. A convenient sample of patients were recruited for this study. Consenting patients were assessed for compliance to therapy based on the Moriski scale and missing day's role $\left[{ }^{6}\right]$. The study population consisted of patients on anticoagulant therapy in the form warfarin and were being managed in the anticoagulation clinic of Prince Sultan Cardiac Center (PSCC) in Al-Qassim, Kingdom of Saudi Arabia.

Patients whose compliance was > $80 \%$ were informed about the study for possible recruitment. Upon understanding and accepting the policy and procedures to be used, they were asked to sign the informed consent form. Care was taken to ensure patient confidentiality.

\section{INCLUSION CRITERIA}

Patients with various cardiac indications were enrolled if they fulfilled the following criteria:

1. Current stable therapy on warfarin

2. Treatment compliance of more than 80 $\%[6]$.

3. Understanding of the procedure of the research and could follow simple instructions

4. Willingness to sign the written informed consent form

\section{EXCLUSION CRITERIA}

1. Patients aged $<18$ years.

2. Patients newly started on warfarin and not yet stabilised.

3. Patients with bleeding disorders such as hemophilia

Comparison between the dosing of physician and doses given by computer software was made to evaluate the differences in TTR and dosing, if any. The computer software used was Coagclinic $\AA$ a web based system in the United States, for management of anticoagulation dosing including warfarin, heparin, low molecular weight heparins (LMWHs) and the new oral anticoagulants.

For the purpose of completing this study, appopriate data extraction form was used to collect related data to be analyzed later. The prospective users' perceptions and attitudes toward the implementation of the new software were recorded and the notes taken will be useful in developing recommendations of the usage. The main source of data collected was the INR values recorded at various visits, patients' files in the clinic, and the interviews with 
patients' were considered as a source of some data related to patients' history. After obtaining their consent, 110 patients on warfarin were recruited. The INR was measured using point of care analyzer Coagucheck (Roche) and for any INR value $>4$, additional testing was carried out using i-Stat analyzer (Abbott). This method was evaluated in our center to be sensitive, as Coagucheck was found not to be not very accurate for high INR readings in another study conducted in the same centre (unpublished data).

\section{STATISTICAL ANALYSIS}

The data were all saved in CoagClinic and then exported to Microsoft Excel®. Confounding variables such as sex, compliance, different indications for anticoagulation, were taken into account while carrying out the statistical analysis of the collected data. The data were then were exported to Minitab $\AA$ to be used for statistical analysis and testing the research hypothesis. The power of the hypothesis was used to detect the expected sample size of the study, as the standardized difference was determined. By using the standardized difference, we would have a high chance of detecting a clinically important difference if it exists. The power and level of significance were assigned to be 0.8 , and 0.05 ; respectively.

\section{RESULTS}

Of the 110 patients recruited for the study, 70 patients completed the study and for each patient, four INR values were recorded from 4 consecutive visits before and after implementation of the software. Since our unit of analysis was the INR, we had about 280 samples in each arm. Of these 70 patients completing the study, $42.8 \%$ was male and $56.3 \%$ female.

\section{Descriptive data of sex, indications and TTR}

Looking at the different indications for anticoagulation, there were $57.2 \%$ subjects with atrial fibrillation (AF), 20\% with mitral valve replacement (MVR), 18.5\%, with aortic valve replacement (AVR), and $4.3 \%$ with dual valve replacement (DVR) (Table 1).

As shown in Table 2, there is a significant difference between the dosing of the physicians at the clinic and the doses generated by the computer software since the calculated t-value is higher than the indexed one $(p \leq 0.05)$.

\section{Impact of CoagClinic, gender and indications on TTR and dosing}

After controlling all the confounders, including demographics and prescribers, we found that the percentage of patients kept at the TTR by physicians was $26 \%$, as $71 \%$ for the software within six month of the commencement of its application $A$ significant difference ( $p=0.015$ ) was found between physicians' dosing and the dosing generated by the computer software (table 3). Furthermore, there was no significant association between different indications for anticoagulation therapy and the calculated TTR $(p=0.61)$. Likewise, there was no significant association between gender and the calculated TTR $(p=0.59)$.

Table 1: Patient demographics and indications for anticoagulation

\begin{tabular}{|c|c|c|c|}
\hline \multicolumn{2}{|c|}{ Total no of patients } & ale & Female \\
\hline 70 & Indicatio & $\begin{array}{l}42.9 \% \\
\text { or anticoagulation* }\end{array}$ & $(40) 57.1 \%$ \\
\hline $\begin{array}{l}\text { Atrial fibrillation } \\
\text { No }(\%)\end{array}$ & Mitral valve replacement & $\begin{array}{l}\text { Aortic valve } \\
\text { replacement }\end{array}$ & Dual valve replacement \\
\hline $40(57.2 \%)$ & $14(20 \%)$ & $13(18.5 \%)$ & $3(4.3 \%)$ \\
\hline
\end{tabular}

Table 2: Paired samples t-test data

\begin{tabular}{lcccc}
\hline Pairing & Mean & sd & t-test & P value \\
\hline Paired physician group with computer system & -1.5654 & 2.094 & -2.796 & 0.015 \\
\hline
\end{tabular}


Table 3: Comparison of TTR of patients on physician-dosed with computer-managed anticoagulation

\begin{tabular}{ccc}
\hline \multicolumn{2}{c}{$\%$ of TTR in therapeutic range } & \\
\hline Physician-dosed & Computer-managed & $P$-value \\
26 & 71 & 0.015 \\
\hline
\end{tabular}

\section{DISCUSSION}

In order to improve the demonstrated lack of success of medical and other staff in achieving INR target ranges, computer assistance of anticoagulant dosage has been advocated which may improve dose management and "time in range". As a result, standards of dosage of the best centers (e.g. $>70 \%$ of time in target INR range) are being made available by computer programs [7]. A CDSS is any software designed to directly aid in clinical decision making in which characteristics of individual patients are matched to a computerized knowledge base for the purpose of generating patient-specific assessments or recommendations that are then presented to clinicians for consideration. Advantages of Computer aided dosing include better levels of control with less dose changes ,this minimizes risk as every time a patient changes dose, there is a possibility for errors and the wrong dose is taken. Medical staff shows natural increased caution in dosing patients at a higher INR range, this caution often means that patients run on the lower end of ranges and below. Computer assisted dosing also allows Standardization of Care across all healthcare professional's managing patients within an organization. Standardization is the first step to improving the whole Quality of Care. It also allows institutions to set their own dosing rules, if required.

However, the safety and effectiveness of such computer assistance requires clinical validation for each and every program. Computerized Decision Support Systems (CDSSs) can enhance clinical performance for drug dosing, preventive care, and other aspects of medical care. Many clinical situations have been investigated to verify the utility of CDSS, few have demonstrated stable effects [8]. One area where success has been reported is the field of oral anticoagulation management. CDSS system has been demonstrated to improve treatment quality in comparison to the manual method. The constant increase of patient numbers and their pressure on thrombosis centers have led to the development of alternative models for delivery of oral anticoagulation therapy [9]. Primary care, General Practitioner, Patient self testing and self management and the use of CDSS has been central to the decentralization process and may be useful in maintaining the efficacy and quality of anticoagulant control. In the future scenario of oral anticoagulant management CDSS will have a pivotal part, General practitioners with the aid of CDSS are able to deliver OAT as well as expert physicians of Thrombosis Centers in terms of time spent by patient in therapeutic range (TTR) [10].

According to Van Leeuwen, the improved control of anticoagulant dosage (ICAD) algorithm is based on a model that comprises the pharmacokinetics and pharmacodynamics of the oral anticoagulant drug, the pharmacokinetics of the prothrombin complex, and the relationship between the activity of the prothrombin complex and the measured INR[11]. Ageno, et al, 1998 shows that the use of computer algorithms to assist physicians with their dosing decisions has been shown to lead to equal or improved quality of control of oral anticoagulant treatment as compared to unassisted dosing [12].

The DAWN AC (anticoagulation) is one of the most widely used computer-dosage programs. Evidence of its value and that of other computer programs has been based previously only on laboratory evidence of "time in target INR range" (TTR).The DAWN AC computer dosage program proved as safe clinically as manual dosage by experienced medical staff [13]. SintromacWeb telecontrol is a new model for management of anticoagulated patients. It is an internet based tool. It was highly accepted and can be used by all patients regardless of their socio demographic characteristics [14]. Moreover, Fitzmaurice, et al. demonstrated that the use of computerized decision support systems (CDSSs) may overcome lack of 
experience, having demonstrated significant improvement in dosing and recall decisions based on the international normalized ratio (INR) result when used in primary care and hospital settings [12]. A CDSS can reduce the reliance on specialist delivery of anticoagulation care, enabling other health care professionals to manage clinics.

Similar to other studies, the statistical analysis didn't show any significant differences in the groups that could be referred to demographic variables, prescribers, or indications. Accordingly, we can generalize the usage of this software for the purpose of the dosing of anticoagulation to improve the effectiveness of the clinic regardless of such confounders.

On the top of this, the optimization process has been conducted fairly in the presence of such high level of noncompliance of $20 \%$. Thus, the software might be also effective to help this cohort of patients to optimize their INR. However, the study was not designed to investigate the effect of sotware on compliance of patients, and an affirmative conclusion is required with another study.

The results obtained by the statistical analysis and the observation of the behavior of prospective users in our study show that the use of computer system in the dosing of anticoagulation therapy has many implications. The use of computer software in the dosing of anticoagulation therapy is to improve the process of calculating the doses and monitoring the therapeutic regimen as well. The results showed that there is significant difference between the doses given by physicians and the doses given by the computer software according to the latest guideline of dosing released by medical institutions that are updated almost every day. Seemingly, differences in dosing have resulted in a better response and longer time within the designated INR range

In comparison to DAWN AC, and other software, CoagClinic has the ACCP (American college of chest physicians) guidelines implemented in it, provides the users with many alerts according to the best published and mostly updated guidelines. In addition to dosing, the user will be alerted on any potential drug-drug interactions and the expected INR changes, allowing the user to work proactively and keep the patient in the TTR as long as possible. Further, it is supplemented with a flow chart on what to do in case of prolonged INRs, and the best clinical recommendations in such scenarios. Several other features have not been utilized by us including, SMS services, heparin dosing, LMWH dosing, and dealing with the new oral anticoagulants. One of the main factors to consider, also, is the price. It is annually-renewed and dependant on number of patients. In our situation, the cost is $\$ 10,000$ with a limit of 3000 patients. Several studies have shown that the CDSSs are cost-effective and the cost is justified. Our case has shown a clear clinical significance, and optimal outcomes.

The application process of computerized dosing system of anticoagulation therapy was passed through difficulties while implementing the process in many aspects. The computer software needs onthe-job (OJT) training programs for the benefit of users. The users of software faced problems such as logging in the software interface and many other problems related to the internet connection since the software is only accessible online. In our situation, the internet speed is acceptable and we had no disconnections during the whole period of the study. However, the most problematic issue that we had is the newly implemented e-prescription model in the hospital, leading to duplication, as we have to deal with two programs at the same time. This has restricted the optimal utilization of the software.

\section{CONCLUSION}

The use of CoagClinic improves the effectiveness of the anticoagulation dosing process and results in better TTR.

\section{CONFLICT OF INTEREST}

The authors hereby declare that they are not in any way associated with the manufacturers of the Coagclinic software and we have not received assistance in any way from the firm.

Trop J Pharm Res, December 2013;12 (6): 1069 


\section{ACKNOWLEDGEMENT}

We would like to express our gratitude to University Al-Qassim and Prince Sultan Cardiac Center, Al-Qassim district, Saudi Arabia for supporting this research.

\section{REFERENCES}

1. ${ }^{1}$ Holbrook AM, Pereira JA, Labiris $R$, McDonald $H$ Douketis JD, Crowther M, Wells PS . Systematic overview of warfarin and its drug and food interactions. Arch Intern Med 2005; 165 (10): 1095-106.

2. Freedman MD. Oral anticoagulants: pharmacodynamics, clinical indications and adverse effects. J Clin Pharmacol 1992;32 (3): 196-209

3. Sagreiya H, Altman RB. The utility of general purpose versus specialty clinical databases for research: warfarin dose estimation from extracted clinical variables. J Biomed Inform 2010 ; 43(5): 747-751

4. Ryan F, Byrne S, O'Shea S. Managing oral anticoagulation therapy: improving clinical outcomes. A review. J Clin Pharm Ther 2008; 33(6): 581-590.

5. Veeger NJ, Piersma-Wichers M, Tijssen JG, Hillege HL, Van der Meer J. Individual time within target range in patients treated with vitamin $\mathrm{K}$ antagonists: main determinant of quality of anticoagulation and predictor of clinical outcome. A retrospective study of 2300 consecutive patients with venous thromboembolism. Br J Haematol 2005; 128(4): 513-519

6. O. Wang Y, Kong MC, Ko Y. Psychometric properties of the 8-item Morisky Medication Adherence Scale in patients taking warfarin. Thromb Haemost 2012; 108 (4): 789-795.

7. Poller L, Shiach CR, MacCallum PK, Johansen AM, Munster AM, Magalhaes A, Jespersen J. Multicentre randomised study of computerized anticoagulant dosage. European Concerted Action on Anticoagulation. Lancet. 1998; 352(9139): 1505-1509.
8. Hunt DL, Haynes RB, Hanna SE, Smith K. Effects of Computer-Based Clinical Decision Support Systems on Physician Performance and Patient Outcomes: A Systematic Review. JAMA 1998; 280(15 ): 1339 -1346.

9. Fitzmaurice $D A$, Hobbs FD, Murray ET, Holder RL, Allan TF, Rose PE. Oral anticoagulation management in primary care with the use of computerized decision support and near-patient testing: a randomized, contolled trial. Arch Intern Med 2000; 160(15): 2343-2348.\#Manotti C, Pattacini C, Quintavalla R, Tagliaferri A, Lombardi M, Tassoni M. Computer Assisted Anticoagulant Therapy. Pathophysiol Haemost Thromb 2003/2004; 33: 366-372.

10. Manotti C, Pattacini C, Quintavalla R, Tagliaferri A, Lombardi M, Tassoni M. Computer Assisted Anticoagulant Therapy. Pathophysiol Haemost Thromb 2003/2004; 33: 366-372.

11. Van Leeuwen $Y$, Rombouts EK, Kruithof CJ, Van der Meer FJM, Rosendaal FR. Improved control of oral anticoagulant dosing: a randomized controlled trial comparing two computer algorithms. J Thromb Haemost 2007; 5: 16441649.

12. Ageno W, Turpie AG. A randomized comparison of a computer-based dosing program with a manual system to monitor oral anticoagulant therapy. Thromb Res 1998; 91: 237-240.

13. Poller L, Keown M, Ibrahim S, Lowe G, Moia M, Turpie $A G$, Roberts $C$, van den Besselaar AM, van der Meer FJ, Tripodi $A$ et al; European Action on Anticoagulation (EAA). A multicentre randomised assessment of the DAWN AC computer-assisted oral anticoagulant dosage program. Thromb Haemost. 2009; 101(3): 487-494

14. Ferrando F, Mira Y, Conteras MT, Aquado C, Aznar JA. Implementation of SintromacWeb(R), a new internet-based tool for oral anticoagulation therapy telecontrol: Study on system consistency and patient satisfaction. Thromb Haemost 2010; 103(5): 1091-110. 